\title{
Design of real-time T-S fuzzy controller based on DSP and its application in Brushless DC motor control
}

\author{
Wu Lin ${ }^{1, ~ a ~, ~ M a ~ X i a o f e n g ~}{ }^{2, b}$, Shi Fuming ${ }^{3, c}$, Zhong Xin ${ }^{4, d}$ \\ $1,2,3,4$ School of Mechanical Engineering, University of Science and Technology Beijing, \\ Haidian District, Beijing 100083, China \\ a,b,c,d wurobot@163.com
}

Keywords: Fuzzy control, Takagi-Sugeno model, Digital signal processor, Brushless DC motor.

\begin{abstract}
A simplified fuzzy control algorithm is proposed, which divides the input and output space of the system into a complete fuzzy pattern set. It also searches for the fuzzy mode corresponding to the real - time input. The whole system is simplified. On this basis, the fuzzy controller which cored as Digital signal processor (DSP) is designed and its DC brushless motor control applications is described. The experimental results show that the fuzzy controller has the characteristics of strong real-time performance, fast response and high precision.
\end{abstract}

\section{Introduction}

With the development of fuzzy control theory, various types of fuzzy control systems based on Mamdani semantic model and Takagi-Sugeno analytic model have emerged. In the actual production process, based on the Mamdani model, the fuzzy controller implemented by look-up table method or simple reasoning method has been widely used. However, for the Takagi-Sugeno model (referred to as TS model), the latter The solution form is a combination of conventional control theory and fuzzy control, which makes it possible to analyze the fuzzy control system by using the existing control theory. But, because the TS model needs to determine more parameters and complicated reasoning, it is only used for the theoretical analysis. The actual use of TS-type fuzzy controller has not been reported. In this paper, the T-S model is studied, and a practical fuzzy control algorithm is obtained by simplifying the reasoning process.

\section{Real-time T-S Fuzzy Controller Algorithm based on DSP}

\section{A. Algorithm Construction}

Based on the T-S model, the $\mathrm{m}$ rule is used as the reference rule base for the controller. For any real-time input, fuzzy rule recognition is used to find a rule that reflects the input situation in the rule base. Based on this, the whole rule base is simplified and the control quantity is obtained. For the given controlled object, take $\mathrm{X}_{1}, \mathrm{X}_{2}, \ldots, \mathrm{X}_{\mathrm{n}}$ as the controller input language variables, $\mathrm{Y}_{1}, \mathrm{Y}_{2}, \ldots$, $\mathrm{Y}_{\mathrm{q}}, \mathrm{Y}$ for the rule after the output variables. For the sake of convenience, each input language variable takes the same number of language values and the same form of membership function, so that the processing is reasonable, where the values are as follows: $\{\mathrm{P} \mathrm{N}\}$. Here, $\mathrm{P}$ means "positive" and $\mathrm{N}$ is "negative". In practical applications, the different number of language values and different forms of membership function could be selected. Consider the following set of reference control rules:

$$
\begin{aligned}
& \mathrm{R}^{\mathrm{i}}: \text { if } \mathrm{x}_{1} \text { is } L_{1}^{i} \text { and } \ldots \text { and } \mathrm{X}_{\mathrm{n}} \text { is } L_{n}^{i} \text { then } \mathrm{y}_{\mathrm{i}}=P_{0}^{i}+P_{1}^{i} \mathrm{x}_{1}+\ldots+P_{n}^{i} \mathrm{x} \\
& (\mathrm{i}=1,2, \ldots, \mathrm{q})
\end{aligned}
$$

Where $\mathrm{X}_{1}, \mathrm{X}_{2}, \ldots, \mathrm{X}_{\mathrm{n}}$ are the input variables; $L_{1}^{i}, L_{2}^{i}, \ldots L_{n}^{i}$, are the true values of the language corresponding to the input variables in the $\mathrm{i}$-th reference rule; $\mathrm{Yi}$ is the output of the latter, and $P_{1}^{i}$, $P_{2}^{i}, \ldots P_{n}^{i}$ is the $\mathrm{i}$-th Posterior part coefficient. The corresponding value of the language 
corresponding to each input variable in the rule base is converted into the fuzzy number form in the corresponding domain. The above rules can be written as matrix:

$$
\begin{aligned}
L & =\left[\begin{array}{cccc}
l_{11} & l_{12} & \ldots & l_{1 n} \\
l_{21} & l_{22} & \ldots & l_{2 n} \\
\ldots & \ldots & \ldots & \ldots \\
l_{q 1} & l_{q 2} & \ldots & l_{q n}
\end{array}\right] \quad P=\left[\begin{array}{cccc}
P_{11} & P_{12} & \ldots & P_{1 n} \\
P_{21} & P_{22} & \ldots & P_{2 n} \\
\ldots & \ldots & \ldots & \ldots \\
P_{q 1} & P_{q 2} & \ldots & P_{q n}
\end{array}\right] \\
\mathrm{X} & =\left(\mathrm{X}_{1}, \mathrm{X}_{2}, \ldots, \mathrm{X}_{\mathrm{n}}\right) \quad \mathrm{Y}=\left(\mathrm{Y}_{1}, \mathrm{Y}_{2}, \ldots, \mathrm{Y}_{\mathrm{q}}\right)
\end{aligned}
$$

$\mathrm{L}$ is the former language value expressed by the fuzzy number, $\mathrm{P}$ is regular posterior part array $\mathrm{X}$, $\mathrm{Y}$ is the input and output vector. Set a sampling time system real-time input accurate amount as $\mathrm{I}_{\mathrm{t}}=\left(\mathrm{i}_{1}\right.$, $\left.\mathrm{i}_{2}, \ldots \mathrm{i}_{\mathrm{n}}\right)$, after blurred, a set of input fuzzy language values can be obtained:

$\mathrm{I}_{\mathrm{t}}=\left(\begin{array}{llll}\mathrm{L}_{1} & \mathrm{~L}_{2} & \ldots & \mathrm{L}_{\mathrm{n}}\end{array}\right)$

Written in the form of fuzzy numbers:

$\mathrm{I}_{\mathrm{tL}}=\left(\begin{array}{llll}1_{1} & 1_{2} & \ldots & 1_{\mathrm{n}}\end{array}\right)$

In the following, the rule that is closest to the input is found from the reference rule base, that is, the Control Rules Center. Write $\mathrm{L}$ in the form of a row vector, ie:

$\mathrm{L}=\left[\begin{array}{llll}\mathrm{L}_{1} & \mathrm{~L}_{2} & \ldots & \mathrm{L}_{\mathrm{Q}}\end{array}\right]^{\mathrm{T}}$

Where $\mathrm{L}_{\mathrm{i}}=\left(\mathrm{l}_{\mathrm{i} 1} \mathrm{l}_{\mathrm{i} 2} \ldots \mathrm{l}_{\mathrm{in}}\right)$ is called fuzzy mode. In this way, q fuzzy mode is determined by the $\mathrm{L}$ matrix in (2). There is something need to emphasize. q fuzzy mode should cover the entire controller, that is, the rule base should be completed.

Calculate the Euclid distance and the maximum Euclid distance between (4) and each ambiguous mode $\mathrm{L}_{\mathrm{i}}$ :

$$
\begin{aligned}
& \operatorname{Ei}\left(I_{t l}, L_{i}\right)=\left\|L_{t L}-L_{i}\right\|=\sqrt{\sum_{j=1}^{n}\left(l_{j}-l_{i j}\right)^{2}} \\
& E=\max _{i=1}^{q}\left[E_{i}\left(I_{t l}, L_{i}\right)\right]=\max _{i=1}^{q}\left(\left\|L_{t L}-L_{i}\right\|\right)
\end{aligned}
$$

At the same time, $\mu_{L k}\left(I_{t l}\right)=\max \left[\mu_{L 1}\left(I_{t l}\right) \cdot \mu_{L 2}\left(I_{t l}\right), \ldots . \mu_{L q}\left(I_{t l}\right)\right]$

For the real-time input $\mathrm{I}_{\mathrm{tL}}$, it is also the membership of the fuzzy mode $\mathrm{L}_{\mathrm{i}}$. Using the maximum membership principle, you can get "control rule center", if there is:

$$
\mu_{i}\left(I_{t l}\right)=1-\frac{E_{i}\left(I_{t L}, L_{i}\right)}{E}
$$

It is assumed that the input I priority belongs to the L mode, and the "control rule center" is $\mathrm{R}^{\mathrm{k}}$. According to rule $\mathrm{R}$, the control rule base can be simplified as:

$\mathrm{R}^{1}$ : if $\mathrm{x}_{1}$ is $L_{1}^{1}$ : and... and $\mathrm{x}_{\mathrm{n}}$ is $L_{n}^{1}$ : Then $\mathrm{y}_{1}=\beta_{1} \mathrm{y}_{\mathrm{k}}$

$\mathrm{R}^{\mathrm{k}}$ : if $\mathrm{x}_{1}$ is $L_{1}^{k}$ and... and $\mathrm{x}_{\mathrm{n}}$ is $L_{n}^{k}$ : Then $\mathrm{y}_{\mathrm{k}}=\beta\left(P_{0}^{(k)}+P_{1}^{(k)} \mathrm{x}_{1}+\ldots+P_{n}^{(k)} \mathrm{x}_{\mathrm{n}}\right)$

Where $\beta 1, \beta 2, \ldots \beta q$ are the posterior part ratio coefficients.

Taking into account the input and the fuzzy mode difference, take $\beta \mathrm{i}=u L I$ (ItL), the use of gravity method to solve the fuzzy, available controller output:

Where $\varpi_{i}$ is the strength of the former i rule. 


\section{Design of Real-time T-S Fuzzy Controller based on DSP and Its Application in DC Brushless Motor Control}

\section{A. Based on DSP motor control system hardware platform structures \\ 1) Selection of microprocessors.}

Digital Signal Processing (DSP) has become a mature technology, and applications gradually replace the traditional analog signal processing system. DSP is more suitable for complex motor control systems. In particular, the digital control system can be programmed to achieve different complex algorithms, so that researchers could achieve the new algorithm, the new theory of debugging and implementation easily. The general motor digital control platform should include digital signal processor core circuit, peripheral device circuit, communication circuit, power circuit and other circuits and cA\} interface, DART interface, JTAG interface and other interfaces.

\section{2) PWM pulse signal generation and processing.}

The 28335 ePWM module has six ePWM submodules including ePWMx, each aisle consists of two PWM outputs: EPWMxA and EPWMxB. The current bridge in the control circuit has six power switches, and the control signals of the two power switches on each arm are related, so only the first three ePWM sub-modules ePWM1, ePWM2, and ePWM3 are used. The control signal includes EPWM1A and EPWM1B, EPWM2A and EPWM2B, EPWM3A and EPWM3B respectively. By the processor chip pin output control signal load capacity is limited, where the choice of chip 74HC245, the specific circuits are shown in Figure 1. EPWM1A is corresponding to PWM1 and EPWM1B is corresponding to PWM2. After the power amplification, there are corresponding to XPWM1 and XPWM2, which is also used the rest of the signal. In order to prevent the impact of the noise signal on the processor and its circuit, the pulse signal after the power amplification also needs to be isolated. Optocoupler gate chip HCPL-0631 is selected and the circuit is shown in Figure 2. The two-conversion is only listed in this figure.
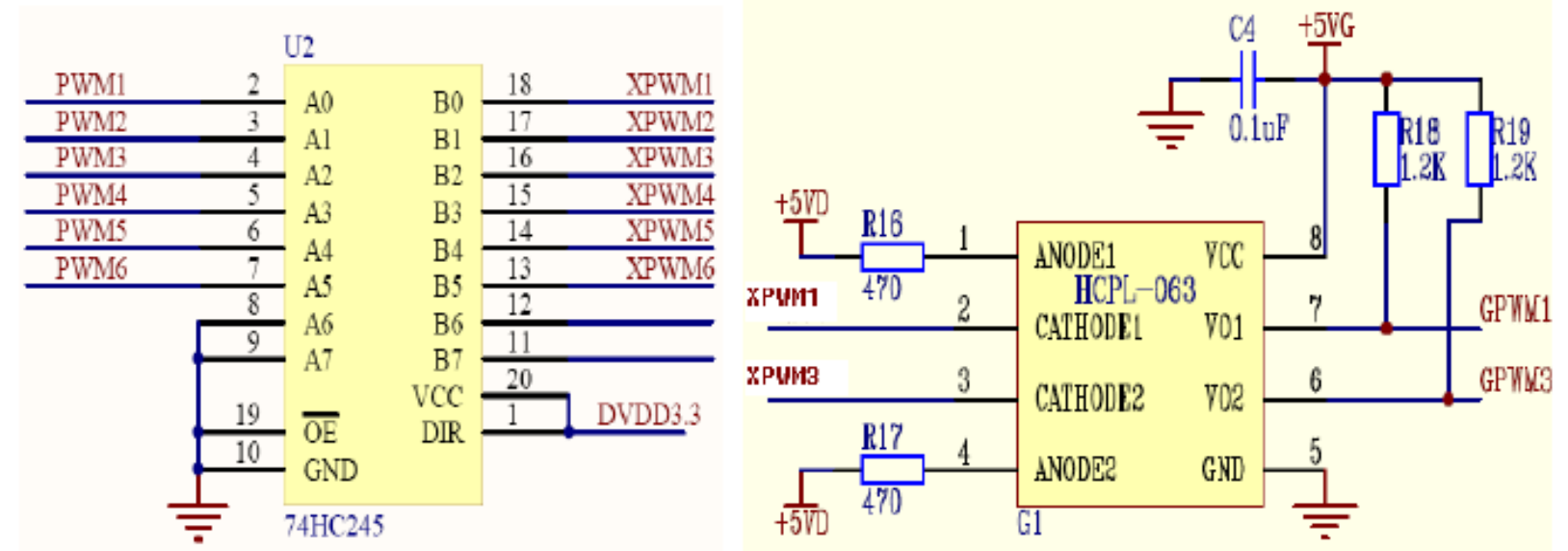

Figure 1 PWM power amplifier circuit schematic Figure 2 PWM light accident isolation circuit schematic

\section{3) Intelligent power module circuit (IMF)}

IPM module is dedicated to drive and control a variety of industrial and civil, single-phase and the new intelligent power module of three-phase motor. The output power components and drive circuit, a variety of protection circuit is integrated in the same module. It is not only has compact structure, low cost, but also the overall performance and reliability of the system are greatly improved. In this paper, the drive circuit is based on three-phase inverter driver integrated chip IR2163 and field effect transistor IRF3205, Circuit is shown in Figure 3, Figure 4. 


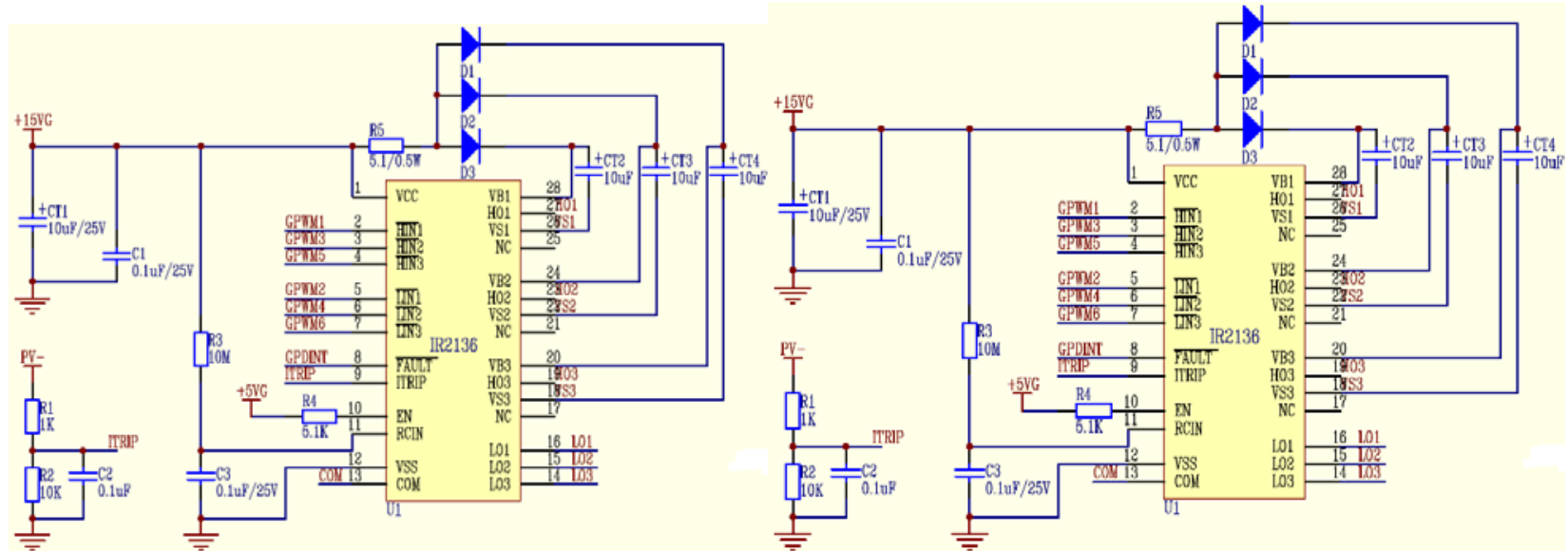

Figure 3 IPM drive circuit schematic diagram

Figure 4 IPM power main circuit schematic

\section{4) Measurement circuit of stator current and bus voltage and current}

Both resistance sampling and current sensor could be used as phase current sampling. The linear current sensor ACS712 o ACS712 is a linear current sensor introduced by ALLegro Company. The accurate low bias linear Hall sensor circuit is built in it which could output and test the AC or DC current proportional to the voltage with some characteristics including low noise, fast response time, high sensitivity, and high insulation voltage and so on. Figure 5 is the ACS712 circuit diagram which detects circuit from the pin 1, 2 input, from the pins 3, 4 output, the signal output port output and the measured current value linear relationship between the voltage, the ratio of $100 \mathrm{mV} / \mathrm{A}$. The voltage of the chip is $\mathrm{SV}$, and the voltage range of the output signal is $2.5-\mathrm{SV}$. If the supply voltage is $3.3 \mathrm{~V}$, the voltage range of the output signal is $1.65-3.3 \mathrm{~V}$. Figure 6 is the bus voltage detection circuit diagram which is used to achieve bus voltage signal acquisition.

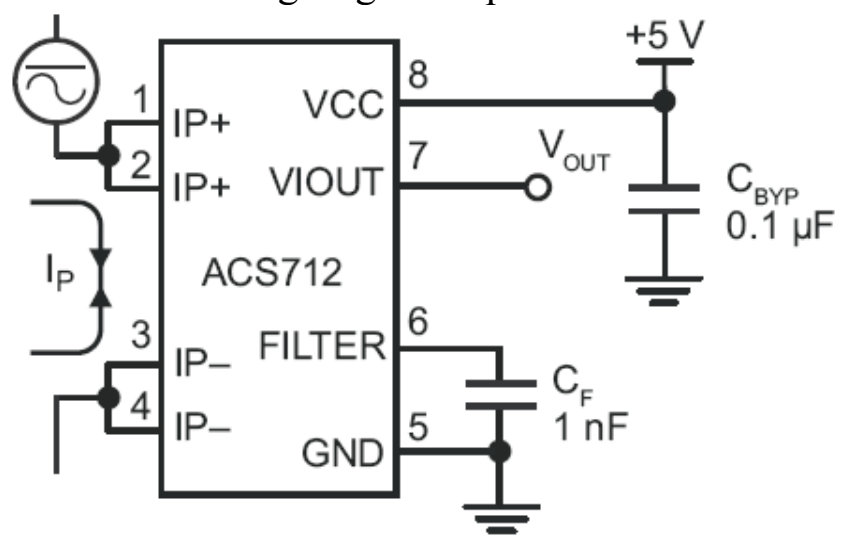

Figure 5 ACS712 linear current sensor circuit diagram

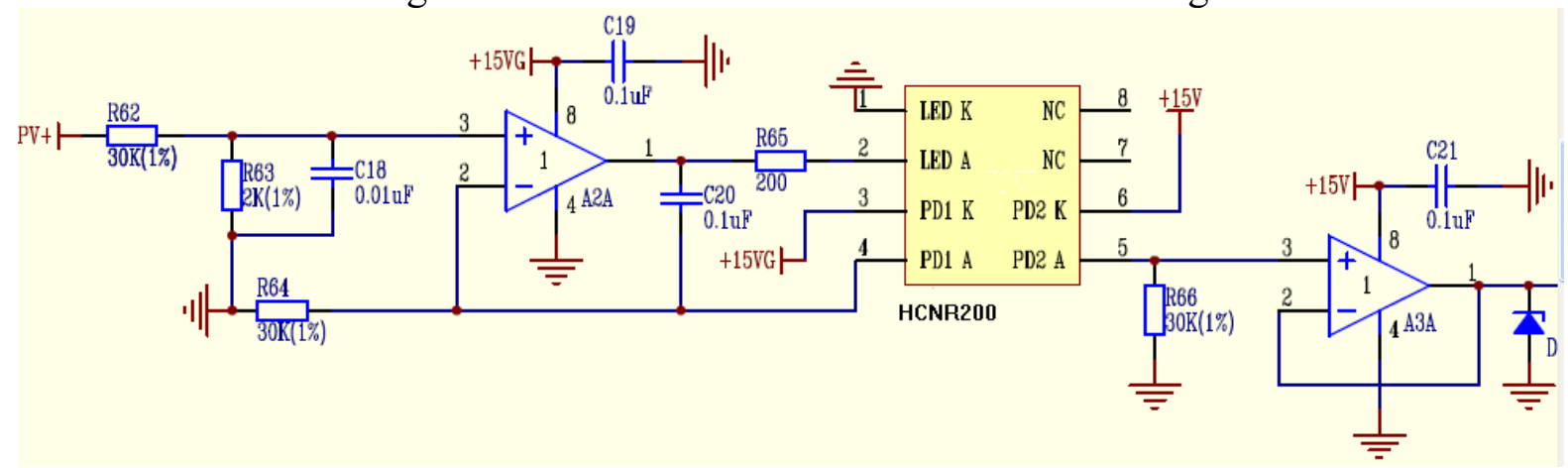

Figure 6 bus voltage detection circuits

\section{B. Based on DSP motor control system hardware platform structures}

In addition to complete the task of motor-driven, modern motor control system is used to complete a number of other ancillary tasks, such as communication with the host, the motor running 
the parameters of detection. As the basic framework for software design, the real-time operating system $\mathrm{uC} / \mathrm{OS}-\mathrm{II}$ ported to the control system platform. Putting the data detection in the motor control process, algorithm calculation, pulse output and capture and host communication operations established in the operating system and assigned different prioprities. And then the operating system is managed and implemented at the same time.

\section{Conclusion}

This paper presents a simplified fuzzy control algorithm. Based on the realization of digital signal processor, the algorithm is applied to the control of DC brushless motor. The resulting fuzzy controller has high accuracy, good real-time and dynamic characteristics. With the digital signal processor as the core, the use of DSP high computing speed could be designed to include complex control algorithms and a variety of functions (such as communications, etc.) controller and this technology can be applied widely.

\section{References}

[1]Huangyuan Wu, Shuanghong Wang, Chenglin Gu, Shiying Duan,Keran Shao. Design of Improved Fuzzy Logic Controller for Built - in Permanent Magnet Synchronous Motor [J]. Journal of China Electromechanical Engineering, 2013,33:68-75+9.

[2]Zhanming Li,Yongjiang Zhang. Design of Fuzzy Controller Based on Computational Fuzzy Reasoning Algorithm [J]. Computer Engineering and Applications,2014,14:259-264.

[3]Dongqi Liu,Yaonan Wang,Yongpeng Shen. Control Strategy of Electric Vehicle V2G Intelligent Charging Station Based on T-S Fuzzy Controller [J]. Journal of Electrotechnical Society, 2016,02:206-214.

[4]Xiaoqian Zhang, Xiaoru Song. Simulation Research on Network Control System Based on T - S Fuzzy Controller [J]. Computing Technology and Automation,2017,02:37-40.

[5]Haitao Wu,Yize Sun, Zuo Meng. Application of Particle Swarm Optimization Fuzzy Controller in Maximum Power Tracking of Photovoltaic Power System [J]. Journal of China Electromechanical Engineering ,2011,06:52-57. 